\title{
Effect of Curing Conditions on the Freeze-Thaw Durability of Self-Consolidating Concrete Including Fly Ash
}

\author{
Nesibe Gozde Ozerkan and Ismail Ozgur Yaman
}

\begin{abstract}
This paper presents the effect of curing conditions on freeze-thaw durability of self-consolidating concrete. In order to determine the effect of curing conditions on the durability properties of self-consolidating concrete, some specimens were cured in air and the others in water. Moist-cured (M-C) specimens were kept in water for 14 days at a temperature of $23 \pm 2^{\circ} \mathrm{C}$ before they were subjected to freeze-thaw cycles. Air-cured (A-C) specimens were however left in ambient laboratory conditions and were saturated in water for a day before they were subjected to the same freeze-thaw cycles. From the permeability tests, it was concluded that air cured specimens have higher permeability. Furthermore, an increase in fly ash content resulted in a reduction in the permeation properties of self-consolidating concrete. On the other hand, more variations were observed in permeability results since only two specimens were used for permeability tests. During the freezing-thawing test, it was observed that air cured specimens were not affected by freezing-thawing and did not indicate any degradation since they were not totally saturated because of the lack of the saturation period that was employed.
\end{abstract}

Index Terms-Curing, fly ash, freeze-thaw durability, self-consolidating concrete.

\section{INTRODUCTION}

Since drying may remove the water needed for hydration and concrete may not achieve its potential properties in this situation, curing has a strong influence on the properties of hardened concrete such as durability, strength, permeability, and volume stability. Furthermore, inadequate or insufficient curing is one of the main factors contributing to weak, powdery surfaces with low abrasion resistance, and also if the concrete is allowed to dry out quickly, it may undergo considerable early age drying shrinkage [1], [2].

In 1948, Powers studied the relation between the hydration of cement and curing of concrete, and pointed out that the development of both strength and durability in concrete not only depends on the degree to which the cement has hydrated but also the degree to which the pores between the cement particles have been filled with hydration products. He also demonstrated that concrete mixtures with a water to cement $(\mathrm{w} / \mathrm{c})$ ratio less than 0.50 and sealed against loss of moisture cannot develop their full potential hydration due to lack of

Manuscript received February 10, 2013; revised May 17, 2013

N. G. Ozerkan is with the Center for Advanced Materials, Qatar University, Doha, Qatar (e-mail: gozdeozerkan@qu.edu.qa).

I. O. Yaman is with the Civil Engineering Department, Middle East Technical University, Ankara, Turkey (e-mail: ioyaman@metu.edu.tr). water, and such mixtures would therefore benefit from externally applied curing water [3]. High performance concrete has very low water content and the developing capillary pores are consequently very small. Unless the loss of water from the surface of the concrete is prevented, this would lead to plastic shrinkage, and hence the need for wet curing from the earliest possible moment must be continued until the strength of the hydrating cement paste is high enough to resist internal microcracking. Neville and Aïtcin [4] studied the distinct shrinkage behavior of high performance concrete and the reasons for an absolute necessity of wet curing, and they stated that high performance concrete that has not been very well cured will be of poor quality. Porosity and interconnectivity are controlled by the amount of cementitious materials, water content, aggregate grading, degree of compaction, degree of hydration and curing efficiency. On the other hand, intensity and location of interfacial microcracks are determined by the level of external or internal applied stress [2], [5]-[8]. Although the high performance concrete offers better durability properties and the permeability is one of the most important parameter of measuring the durability of concrete, there are very limited research on the permeability of high-performance concrete. One such research was reported by Poon et.al. and Janotka and Bagel and they showed that permeability of all high strength concrete specimens increased drastically with the increase in the temperature, and concrete specimens showed a very low permeability at lower temperature degrees [9], [10].

\section{II.EXPERIMENTAL PROCEDURE}

\section{A. Material Properties and Mixture Proportions}

Throughout the study, in all mixtures a normal Portland cement CEM I 42.5R (PC), which correspond to ASTM Type I cement and low lime fly ash (FA) was used. The chemical composition and physical properties of PC and FA are presented in Table I. Crushed limestone was used as for the fine and coarse aggregate. Two types of coarse aggregate named with a nominal size of $12 \mathrm{~mm}$ had specific gravity of 2.68 and water absorption of $0.42 \%$ and $0.52 \%$, respectively. The fine aggregate had a specific gravity of 2.67 and water absorption of $0.75 \%$. In all concrete mixtures, a polycarboxylic-ether type superplasticizer with a specific gravity of $1.09, \mathrm{pH}$ of 6.6 , and oil alcohol and ammonium salt based air entraining admixture with a specific gravity of 1.02 and a $\mathrm{pH}$ of 10 were used. 
TABLE I: CHEMICAL COMPOSITION AND PHYSICAL PROPERTIES OF PORTLAND CEMENT AND FLY ASH

\begin{tabular}{lcc}
\hline \hline Chemical Composition & PC & FA \\
\hline $\mathrm{CaO}(\%)$ & 64.55 & 5.40 \\
\hline $\mathrm{SiO}_{2}(\%)$ & 19.56 & 51.55 \\
\hline $\mathrm{Al}_{2} \mathrm{O}_{3}(\%)$ & 5.00 & 18.12 \\
\hline $\mathrm{Fe}_{2} \mathrm{O}_{3}(\%)$ & 3.68 & 11.85 \\
\hline $\mathrm{MgO}(\%)$ & 1.57 & 4.63 \\
\hline $\mathrm{SO}_{3}(\%)$ & 2.41 & 0.11 \\
\hline $\mathrm{K}_{2} \mathrm{O}(\%)$ & 0.66 & 1.88 \\
\hline $\mathrm{Na}_{2} \mathrm{O}(\%)$ & 0.77 & 5.65 \\
\hline Loss on Ignition $(\%)$ & 2.89 & 1.34 \\
\hline Physical Properties & & \\
\hline Specific Gravity & 3.09 & 2.18 \\
\hline Blaine Fineness $\left(\mathrm{cm}^{2} / \mathrm{g}\right)$ & 3527 & 3138 \\
\hline \hline
\end{tabular}

Within the scope of experimental program, a total of ten self-consolidating concrete mixtures with four different fly ash content (replaced by $0 \%, 15 \%, 30 \%$ and $45 \%$ of cement content by weight), and with three different air entraining agent content $(0 \%, 0.15 \%$ and $0.3 \%)$ were prepared. All concrete mixtures had the same superplasticizer content as $1.3 \%$ of cementitious materials by weight. During the casting operation, the workability properties of SCCs were observed through, slump flow time and diameter, air content, V-funnel flow time, L-box height ratio, and segregation ratio tests. Hardened properties were evaluated by compressive strength, permeability tests (water absorption, sorptivity and rapid chloride permeability test) and freezing-thawing test. Moreover, to determine the effect of curing conditions on the durability properties of self-consolidating concrete, some specimens were cured in air and the others in water. Moist-cured (M-C) specimens were kept in water for 14 days at a temperature of $23 \pm 2{ }^{\circ} \mathrm{C}$ before they were subjected to freeze-thaw cycles. Air-cured (A-C) specimens were however left in ambient laboratory conditions and were saturated in water for a day before they were subjected to the same freeze-thaw cycles.

\section{B. Tests on Fresh and Hardened Concrete}

In this study, the air content and setting time tests of fresh concrete were determined according to the related ASTM standard test methods. Furthermore, workability properties of SCC mixtures were evaluated through the measurement of slump flow time (T50) to reach a concrete $50 \mathrm{~cm}$ spread circle, slump flow diameter, V-funnel flow time, L-box height ratio and GTM sieve stability according to the methods standardized by Specification and Guidelines for SCC prepared by EFNARC [11]. The hardened concrete properties determined at 14 days of age were compressive strength, absorption, sorptivity and rapid chloride permeability test. Later, the specimens were freezed and thawed in air and the temperature of the specimens was lowered from 4 to $-18{ }^{\circ} \mathrm{C}$ and raised from -18 to $4{ }^{\circ} \mathrm{C}$ in 3 hours by using the climate test cabinet. Temperature variation inside the specimen was monitored by installing a thermocouple into the concrete the interior of concrete specimen reached freezing temperatures of $-18^{\circ} \mathrm{C}$ in about 90 minutes and thawing temperature of $4^{\circ} \mathrm{C}$ in about 75 minutes. The concrete specimens were removed from the cabinet at each 30 cycle to determine the relative dynamic modulus of elasticity by using the resonant frequency method. The test was continued until the relative dynamic modulus of elasticity values of the specimens reached $60 \%$ of the initial modulus or 700 cycles whichever was reached first.

\section{RESUltS AND DISCUSSION}

\section{A. Fresh Concrete Properties}

The workability properties like slump flow time and diameter, V-funnel flow time and L-box height ratio of the fresh concretes are given in Table II. The slump flow diameters of all mixtures were in the range of $66.5-72.5 \mathrm{~cm}$, slump flow times were less $10 \mathrm{~s}$, and the L-box height ratios were between the range of 0.22-1.00. Although all results were not in the range established by EFNARC except the slump flow time and diameter, all concrete mixtures filled the molds by its own weight without the need for vibration and the concrete mixtures were accepted as self-consolidating concrete.

TABLE II: FRESH CONCRETE TEST RESULTS

\begin{tabular}{|c|c|c|c|c|c|}
\hline \multirow[b]{2}{*}{ Mix \# } & \multirow[b]{2}{*}{ Mix Design } & \multirow{2}{*}{$\begin{array}{c}\text { V } \\
\text { Funnel } \\
\text { (s) }\end{array}$} & \multicolumn{2}{|c|}{ Slump Flow } & \multirow{2}{*}{$\begin{array}{r}\text { L Box } \\
\left(\mathbf{h}_{2} / \mathbf{h}_{1}\right)\end{array}$} \\
\hline & & & $\begin{array}{c}D \\
(\mathbf{c m})\end{array}$ & $\begin{array}{l}T_{50} \\
(s)\end{array}$ & \\
\hline 1 & AE0-FA0 & 62 & 70.0 & 6 & 0.22 \\
\hline 2 & AE0-FA15 & 75 & 72.5 & 4 & 0.85 \\
\hline 3 & AE0-FA30 & 85 & 70.5 & 6 & 0.33 \\
\hline 4 & AE0-FA45 & 28 & 75.0 & 5 & 0.94 \\
\hline 5 & AE0.15-FA15 & 13 & 71.5 & 4 & 1.00 \\
\hline 6 & AE0.15-FA30 & 100 & 70.0 & 7 & 0.94 \\
\hline 7 & AE0.15-FA45 & 55 & 68.5 & 9 & 0.55 \\
\hline 8 & AE0.3-FA45 & 26 & 69.5 & 10 & 0.89 \\
\hline 9 & AE0.08-FA15 & 80 & 69.0 & 6 & 0.25 \\
\hline 10 & AE0.3-FA30 & 9 & 66.5 & 6 & 0.88 \\
\hline
\end{tabular}

\section{B. Hardened Concrete Properties}

The hardened properties of SCC mixes evaluated at 14 days of age were compressive strength and permeability tests, and the results are given in Table III. As seen from the table, an increase in fly ash and air entraining agent content resulted in a reduced compressive strength. Moreover, increasing in the fly ash content resulted in a reduction in rapid chloride permeability and sorptivity index values.

Fig. 1, Fig. 2 and Fig. 3 present the effect of fly ash content on the compressive strength, elastic properties and permeability properties, respectively. As seen from Fig. 1, increase in the fly ash content resulted in an increased difference between compressive strength values of moist cured and air cured specimens which were also affected by the amount of air entraining agent. On the other hand, from 
Fig. 2, it can be seen that an increase in fly ash content raised the difference between UPV and resonant frequency values of air cured and moist cured specimens and this result is also compatible with the compressive strength results. Furthermore it can be concluded that air cured specimens have higher permeability. However, in permeability results, there are more variations which can be mostly attributed to the test procedures [Yaman, 2000].

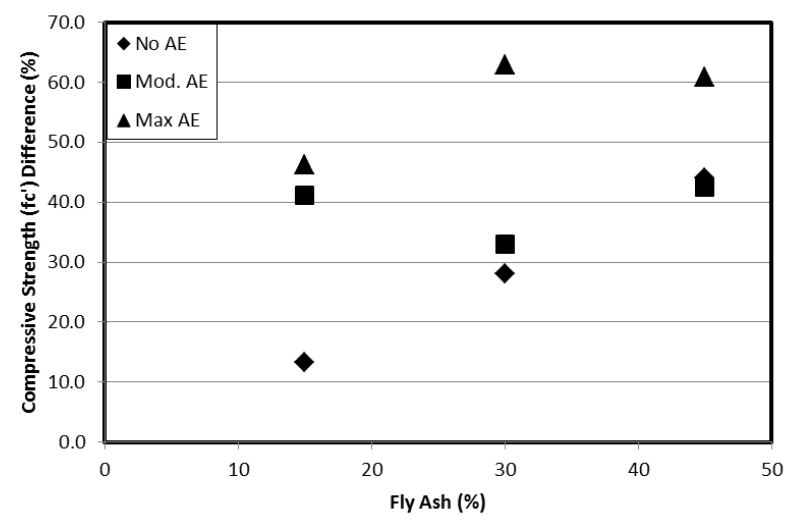

Fig. 1. Relationship between Compressive Strength and Fly Ash Content.

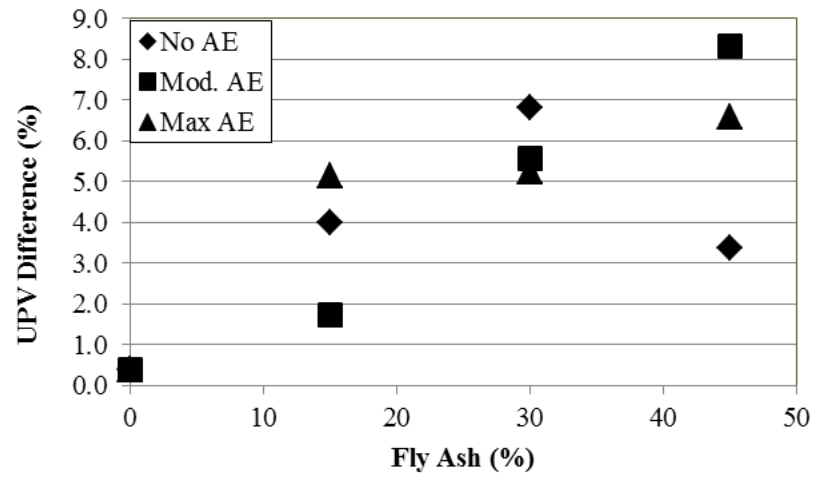

(a) Ultrasonic Pulse Velocity.

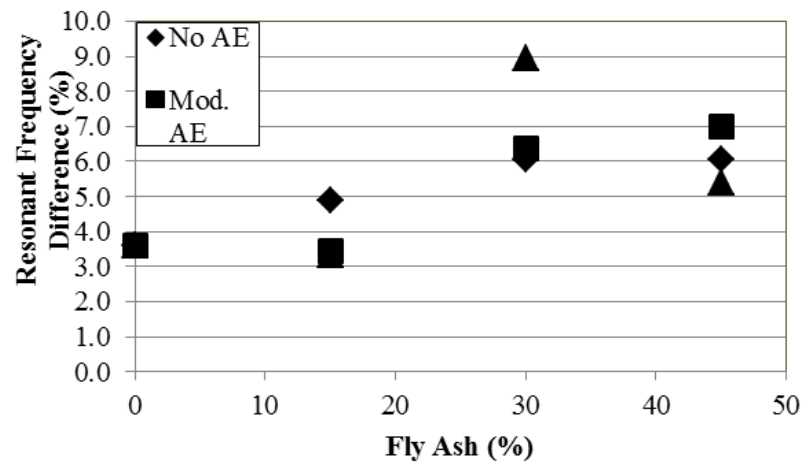

(b) Resonant Frequency.

Fig. 2. Relationship between Elastic Properties and Fly Ash Content.

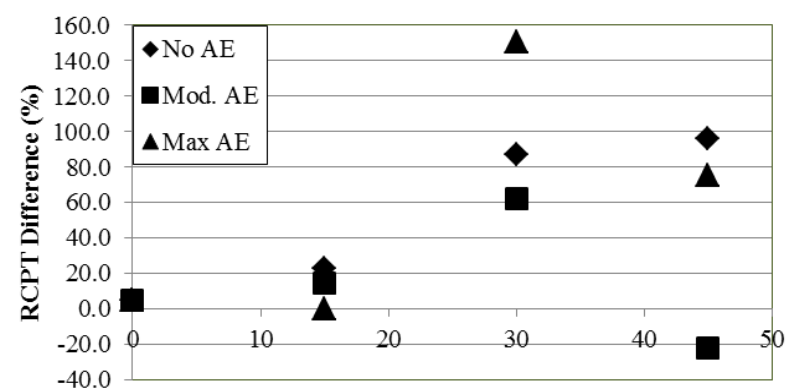

Fly Ash (\%)

(a) Rapid Chloride Permeability Test.

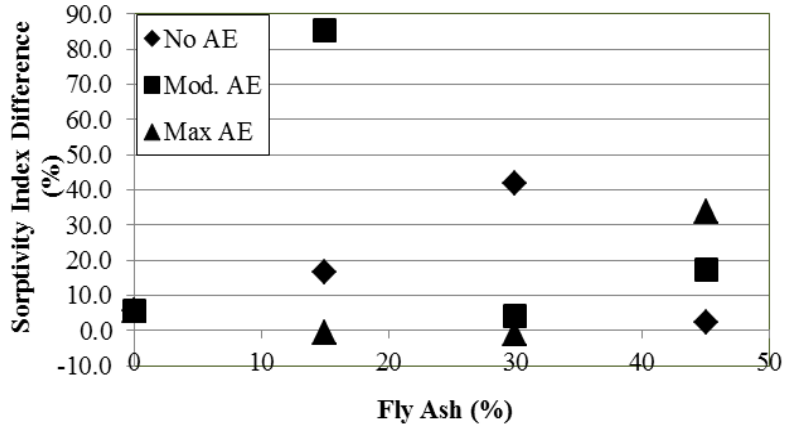

(b) Sorptivity.

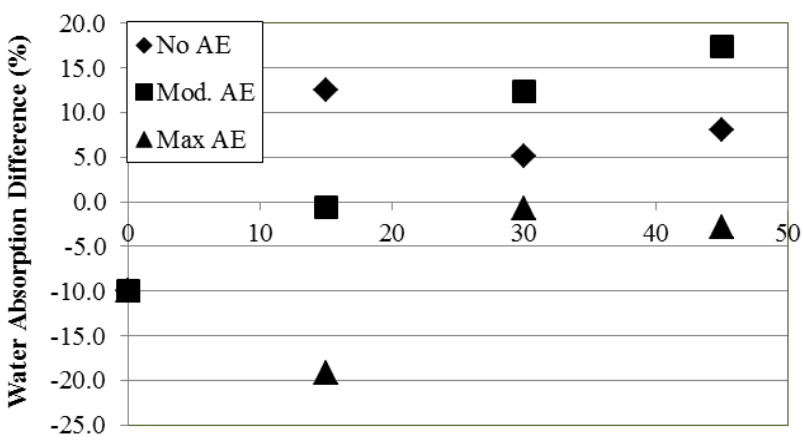

Fly Ash (\%)

(c) Water Absorption.

Fig. 3. Relationship between Permeability and Fly Ash Content

The effect of freezing-thawing is commonly assessed on the basis of the change in the dynamic modulus of elasticity. The dynamic methods employ ultrasonic velocity and mechanical resonant frequency tests. In this study, resonant frequency test was employed to determine the dynamic modulus of elasticity values of SCC cylinder specimens. The dynamic modulus of elasticity of each concrete specimen was calculated at initial condition, and for each 30 freezing-thawing cycles. In Fig. 4 and Fig. 5, resonant frequency values of each mix for both moist cured and air cured specimens for each 30 freezing-thawing cycles are given, respectively.

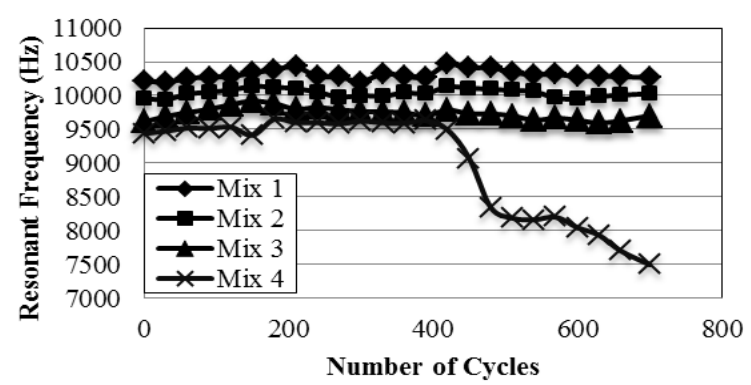

(a) No Air Entraining

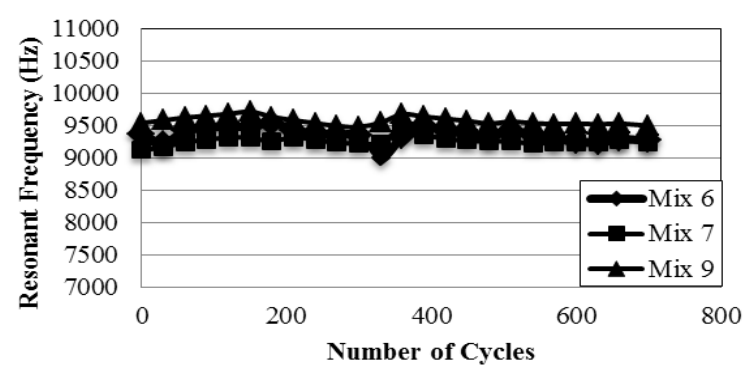

(b) Minimum Air Entraining. 


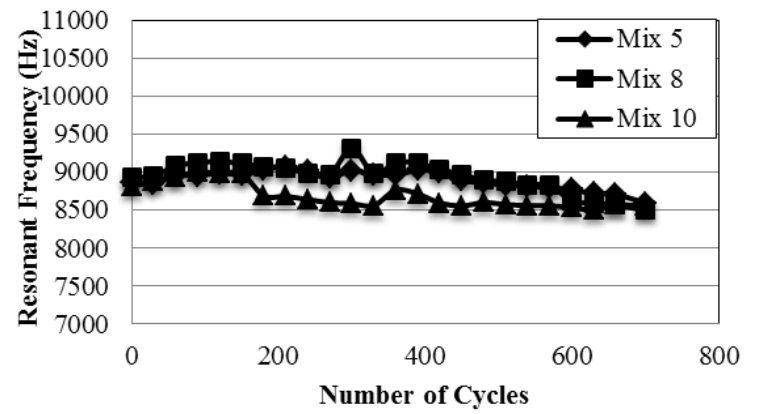

(c) Maximum Air Entraining.

Fig. 4. Resonant Frequency Test Results for Moist Cured Specimens.

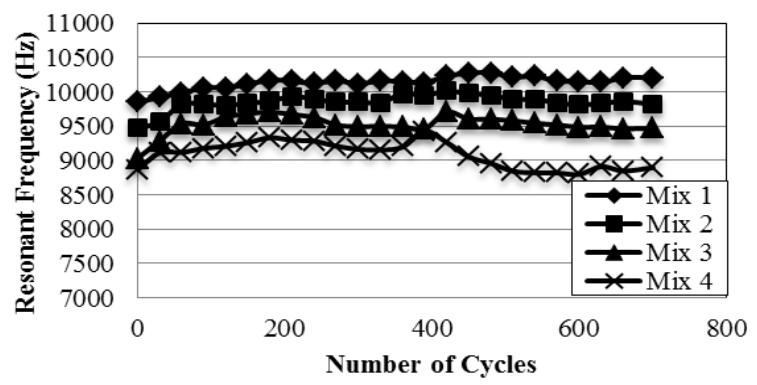

(a) No Air Entraining.

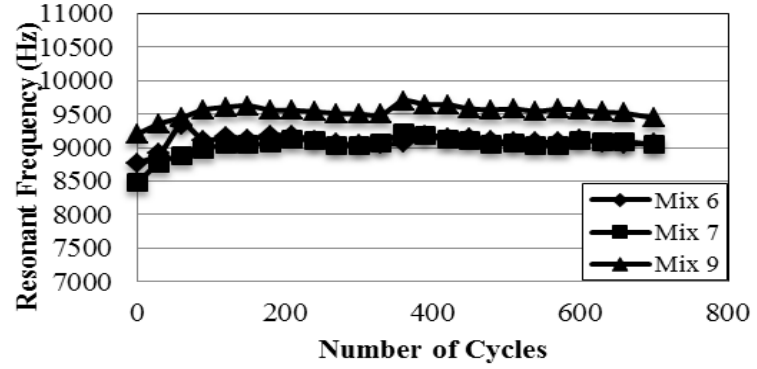

(b) Minimum Air Entraining.

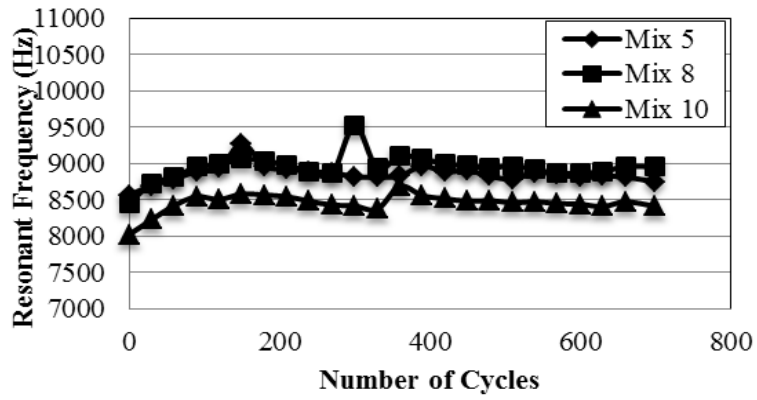

(c) Maximum Air Entraining.

Fig. 5. Resonant Frequency Test Results for Air Cured Specimens.

TABLE III: HARDENED CONCRETE TEST RESULTS BEFORE FREEZING-THAWING

\begin{tabular}{|c|c|c|c|c|c|c|c|c|}
\hline$\underset{\#}{\operatorname{Mix}}$ & Mix Design & $\begin{array}{l}\text { Curing } \\
\text { Condition }\end{array}$ & $\begin{array}{c}\text { Compressive } \\
\text { Strength } \\
\left(\mathbf{k g f} / \mathrm{cm}^{2}\right) \\
\end{array}$ & RCPT & $\begin{array}{l}\text { Sorptivity Index } \\
\left(\mathbf{m m} / \mathbf{m i n}^{1 / 2}\right)\end{array}$ & $\begin{array}{c}\text { Water } \\
\text { Absorption } \\
(\%) \\
\end{array}$ & $\begin{array}{c}\text { Resonant } \\
\text { Frequency (Hz) }\end{array}$ & $\begin{array}{l}\text { UPV } \\
(\mathrm{m} / \mathrm{s})\end{array}$ \\
\hline \multirow{2}{*}{1} & AE0-FA0 & $\mathrm{M}-\mathrm{C}$ & 670 & 2741 & 0.0107 & 4.79 & 10218 & 4902 \\
\hline & AE0-FA0 & A-C & 520 & 2864 & 0.0113 & 4.31 & 9848 & 4884 \\
\hline \multirow{2}{*}{2} & AE0-FA15 & $\mathrm{M}-\mathrm{C}$ & 579 & 2714 & 0.0110 & 4.74 & 9958 & 4923 \\
\hline & AE0-FA15 & A-C & 502 & 3328 & 0.0128 & 5.33 & 9471 & 4727 \\
\hline \multirow{2}{*}{3} & AE0-FA30 & $\mathrm{M}-\mathrm{C}$ & 529 & 1934 & 0.0086 & 4.71 & 9613 & 4888 \\
\hline & AE0-FA30 & A-C & 381 & 3615 & 0.0122 & 4.95 & 9032 & 4555 \\
\hline \multirow{2}{*}{4} & AE0-FA45 & $\mathrm{M}-\mathrm{C}$ & 413 & 1916 & 0.0093 & 4.74 & 9439 & 4706 \\
\hline & AE0-FA45 & A-C & 231 & 3752 & 0.0095 & 5.12 & 8865 & 4547 \\
\hline \multirow{2}{*}{5} & AE0.15-FA15 & $\mathrm{M}-\mathrm{C}$ & 301 & 2920 & 0.0156 & 6.19 & 8857 & 4489 \\
\hline & AE0.15-FA15 & A-C & 162 & 3236 & 0.0155 & 5.00 & 8564 & 4259 \\
\hline \multirow{2}{*}{6} & AE0.15-FA30 & $\mathrm{M}-\mathrm{C}$ & 437 & 3179 & 0.0101 & 4.54 & 9371 & 4722 \\
\hline & AE0.15-FA30 & A-C & 293 & 5142 & 0.0105 & 5.10 & 8773 & 4459 \\
\hline \multirow{2}{*}{7} & AE0.15-FA45 & $\mathrm{M}-\mathrm{C}$ & 367 & 3392 & 0.0086 & 4.67 & 9118 & 4691 \\
\hline & AE0.15-FA45 & A-C & 211 & 2648 & 0.0101 & 5.48 & 8481 & 4301 \\
\hline \multirow{2}{*}{8} & AE0.3-FA45 & $\mathrm{M}-\mathrm{C}$ & 291 & 2565 & 0.0086 & 5.51 & 8932 & 4613 \\
\hline & AE0.3-FA45 & A-C & 114 & 4496 & 0.0115 & 5.35 & 8451 & 4309 \\
\hline \multirow{2}{*}{9} & AE0.08-FA15 & $\mathrm{M}-\mathrm{C}$ & 583 & 5237 & 0.0061 & 4.95 & 9535 & 4752 \\
\hline & AE0.08-FA15 & A-C & 343 & 6007 & 0.0113 & 4.92 & 9205 & 4669 \\
\hline \multirow{2}{*}{10} & AE0.3-FA30 & $\mathrm{M}-\mathrm{C}$ & 423 & 3762 & 0.0110 & 5.28 & 8808 & 4479 \\
\hline & AE0.3-FA30 & A-C & 157 & 9437 & 0.0109 & 5.24 & 8021 & 4244 \\
\hline
\end{tabular}

As seen from Fig. 4 and Fig. 5 for those mixes that do not contain any air-entrainment the initial resonant frequency values are higher. As the air-entrainment level is increased there is a reduction in the initial resonant frequency of the concrete simply because of the increase in the porosity leading to a decrease in the modulus of elasticity. Moreover, except for the mix those do not contain any air entrainment and maximum amount of fly ash, most of the mixes are resistant to freezing and thawing cycles.

\section{CONCLUSION}

This paper presents the effect of curing conditions on freeze-thaw durability of self-consolidating concrete. In 
order to determine the effect of curing conditions on the durability properties of self-consolidating concrete, some specimens were cured in air and the others in water. At the end of the study, it was observed that

- The difference between the compressive strength, UPV and resonant frequency values of moist cured and air cured specimens increased with increasing fly ash and air entraining agent content. Therefore, special attention should be paid to cure the concrete mixes incorporating higher amounts of fly ash and air entraining agent.

- Air cured specimens have higher permeability. Furthermore, an increase in fly ash content resulted in a reduction in the permeation properties of self-consolidating concrete. On the other hand, more variations were observed in permeability results since only two specimens were used for permeability tests.

- Air cured specimens were not affected by freezing-thawing and did not indicate any degradation since they were not totally saturated because of the lack of the saturation period that was employed.

\section{REFERENCES}

[1] ACI Committee Report 308, Guide to Curing Concrete, ACI, USA; 2001.

[2] P. K. Mehta and P. J. M. Monteiro, Concrete, Microstructure, Properties and Materials, 3rd ed., McGraw-Hill, USA.

[3] T. C. Powers, "A discussion of cement hydration in relation to the curing of concrete," in Proc. Highway Research Board, Washington, D.C., USA, vol. 27, pp. 178-188, 1948.

[4] A. Neville and P. C. Aïtcin, "High perfomance concrete- an overview," Materials Structures, vol. 31, pp. 111-117, 1998.

[5] N. Banthia, A. Biparva, and S. Mindess, "Permeability of concrete under stress," Cement and Concrete Research, vol. 35, pp.1651-1655, Oct., 2004.

[6] S. Lee, "Petrographic evaluation of bridge deck concrete durability," $\mathrm{Ph} . \mathrm{D}$. Thesis, Graduate Faculty of Texas Tech University, Aug., 2001

[7] M. Sahmaran, "Self-compacting concrete with high volumes of fly ash," PhD. Thesis, Department of Civil Engineering, METU, Ankara, Turkey, 2006.

[8] E. Güneyisi, M. Gesoğlu, T. Özturan, and E. Özbay, "Estimation of chloride permeability of concretes by empirical modelling: Considering effects of cement type, curing condition and age," Construction and Building Materials, vol. 23, pp. 469-481, Dec., 2009.
[9] I. Janotka and L. Bagel, "Pore structures, permeabilities, and compressive strengths of concrete at temperatures up to $800^{\circ} \mathrm{C}, " \mathrm{ACI}$ Material Journal, vol. 99, pp. 196-200, 2003.

[10] C.-S. Poon, S. Azhar, M. Anson, and Y.-L. Wong, "Comparison of the strength and durability performance of normal- and high-strength pozzolanic concretes at elevated temperatures," Cement and Concrete Research, vol. 31, no. 9, pp. 1291-1300, 2001.

[11] EFNARC, Specification \& Guidelines for Self-Consolidating Concrete, European Federation for Specialist Construction Chemicals and Concrete Systems, Norfolk, UK, Feb., 2002.

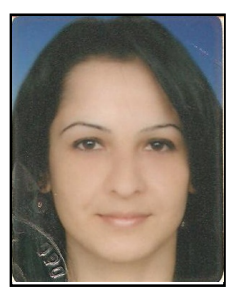

Nesibe Gözde Özerkan was born in Adana, Turkey at 28 February 1979. She received her B.Sc. in Civil Engineering from the Cukurova University, Turkey, in 2002. She received her M.Sc. in January 2006 and Ph.D. in October 2009 from Middle East Technical University, Turkey, both in Civil Engineering.

She worked as a graduate teaching and research assistant in the Civil Engineering Department at Middle East Technical University from September 2003 until March 2009. She joined Materials Technology Unit of Qatar University in September 2009 as an Associate Researcher and now she is working as Assistant Professor/Associate Researcher in Center for Advanced Materials in Qatar University. She has extensive experience in mechanics of construction materials, nondestructive evaluation techniques, material science, image processing, construction materials testing procedures, life cycle assessment and recycling.

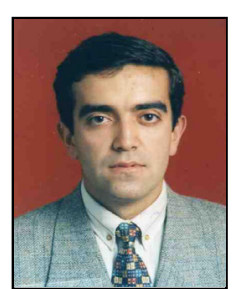

Ismail Özgür Yaman was born in Konya, Turkey at 24 December 1970. He received his B.Sc. in June 1993, M.Sc. in September 1995 and Ph.D. in December 2000 in Civil Engineering from the Middle East Technical University, Turkey.

He worked as a graduate teaching assistant in the Civil Engineering Department at Middle East Technical University from January 1994 until December 1996, and as a graduate research and teaching assistant in the Civil Engineering Department at Wayne State University from January 1997 until August 2000. He worked as Research Associate in Wayne State University from August 2000 until January 2001 and worked as research engineer in Ford Motor Company from February 2001 to 2003. He joined Civil Engineering Department of Middle East Technical University in September 2003 as Assistant Professor and now he is working as Professor $\mathrm{He}$ has extensive experience in mechanics of construction materials, nondestructive evaluation techniques, material science, durability properties of concrete, the evaluation of waste materials in cement and concrete, self -consolidating concrete. 